\title{
Design and Construction of a 2D Metal Organic Framework with Multiple Cavities: A Non-Regular Net with a Paracyclophane that Codes for Multiply-Fused Nodes
}

Giannis S. Papaefstathiou, Tomislav Friščić and Leonard R. MacGillivray*

Department of Chemistry, University of Iowa, Iowa City, Iowa 52242

\section{SUPPLEMENTARY MATERIAL}

Figure S1. TGA trace for 1.

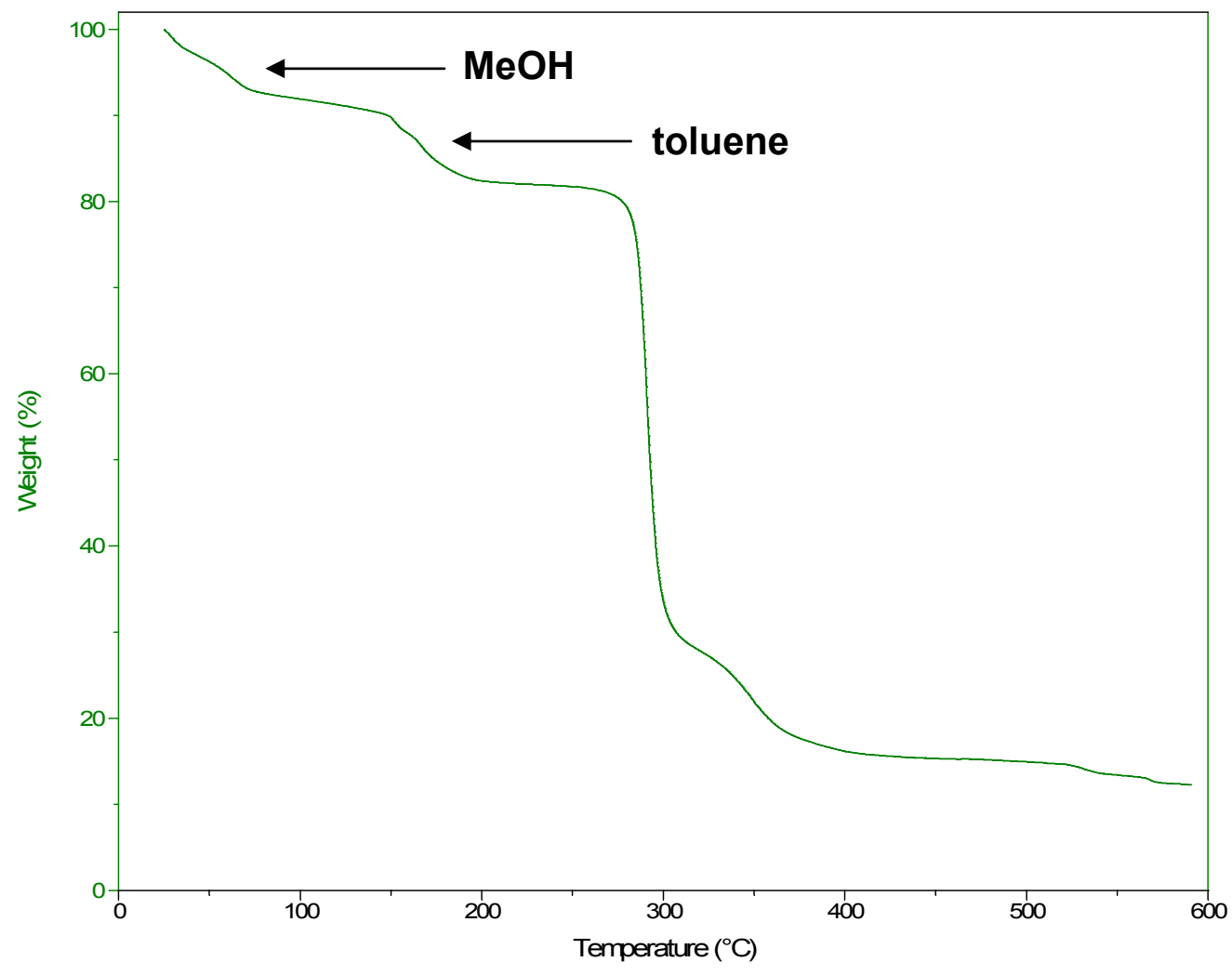

